ELORE (ISSN 1456-3010), vol. $16-1 / 2009$.

Julkaisija: Suomen Kansantietouden Tutkijain Seura ry.

[http://www.elore.fi/arkisto/1_09/kirjat_hovi_01_09.pdf]

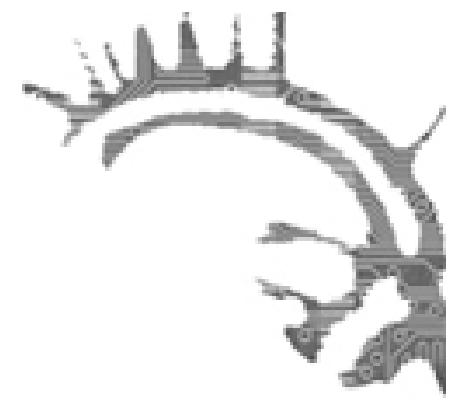

\title{
KIRJA-ARVIO:
}

\section{MitTATILAUSETIIKKAA FOLKLORISTEILLE}

Alver, Bente Gulveig \& Fjell, Tove Ingebjorg \& Oyen, Orjar (eds.): Research Ethics in Studies of Culture and Social Life. Folklore Fellows' Communications 292. Helsinki: Academia Scientiarum Fennica. 232 sivua.

\section{$\underline{\text { Tuija Hovi }}$}

Tutkimusetiikkakirjallisuus on alkanut kasvaa sekä monipuolistua Suomessakin tämän vuosituhannen puolella. Eloren aiemmissa numeroissa on jo ehditty esitellä tuoreeltaan niitä tutkimusetiikan oppaita, jotka on osoitettu laajasti ottaen humanistisen ja yhteiskuntatieteellisen tutkimuksen tekijöille. Arja Kuulan (2006) Tutkimusetiikeka. Aineiston hankinta, käyttö ja säilytys keskittyy aineiston elinkaariajatteluun (ks. 2/2006). Jaana Hallamaan, Veikko Launiksen, Salla Lötjösen ja Olli Löytyn (2006) toimittama Etiikkeaa ibmistieteille koskettelee laajemmin tutkimusprosesseja sekä tiedeyhteisön käytäntöjä (ks. 1/2008). Henriikka Clakeburnin ja Arto Mustajoen (2007) kokoama Tutkijan arkipäivän etiikeka seuraa tutkijan uraa ja osoittaa sen eri vaiheissa esiin nousevia eettisiä kysymyksiä (ks. 2/2008).

Yleisesti hyväksytty tieteellinen käytäntö on Suomessa periaatteellisesti ohjeistettu lainsäädännöllä ja Tutkimuseettisen neuvottelukunnan (2002) evästyksin. Yleispäteviä suuntaviivoja, jotka pätisivät takuuvarmasti kaikilla tutkimusaloilla, on kuitenkin vaikea vetää yksiselitteisesti. Tutkimuseettisen ohjeistuksen tarve on siis myös alakohtaista. Lauri Hongon 1980-luvulla käynnistämä keskustelu kvalitatiivisia aineistoja ja menetelmiä käyttävien folkloristien ja etnologien laajassa kansainvälisessä tiedeyhteisössä kulminoitui aloitteeseen Folklore Fellows Code of Ethics, jonka pohjalta perustettua opinto-ohjelmaa rahoitti Pohjoismainen Ministerineuvosto.

Norjalaisfolkloristien toimittama ja kansainvälisin yhteisvoimin koottu Research Ethics in Studies of Culture and Social Life on julkaistu kunnianosoituksena Lauri 
Hongon pioneerityölle perinteentutkimuksen etiikan määrittelemiseksi. Kirjoittajat ovat folkloristeja, etnologeja sekä kulttuuri- ja sosiaalitieteilijöitä, jotka vuosituhannen taitteessa osallistuivat Hongon Kalevala-instituutin puitteissa organisoimaan tutkimusetiikkaohjelmaan.

\section{Tulkintojen haAsteET}

Kattavassa johdantoartikkelissaan Bente Gulveig Alver ja Ørjar Øyen vetävät selkeät suuntaviivat ja esittelevät teemat, joita muissa artikkeleissa avataan käytännön esimerkkien kautta. Eettisinä kysymyksinä kulttuurintutkija joutuu miettimään tutkittavien anonymisointia, valtasuhteita, tulkintaperspektiivejä, arkaluontoisuutta, läheisyyden ja etäisyyden ulottuvuuksia sekä kerätyn aineiston omistussuhteita ja tekijänoikeuksia. Etnografinen kenttätyö asettaa tekijälleen luonnollisesti monenlaisia sosiaaliseen kanssakäymiseen liittyvä kysymyksiä kaikissa vaiheissaan. Reunaehdoista ja kauniista periaatteista huolimatta kaikkia kysymyksiä ei kuitenkaan voi ennakoida ja ratkaista etukäteen. Tutkimusprosessien keskusteluttaminen antaa kuitenkin näkökulmia ja työkaluja tapauskohtaisten eettisten kysymysten käsittelyyn.

Kenttätyöproblematiikan sinnikäs puiminen jo usean vuosikymmenen ajan on varustanut kulttuurintutkijoita varhaisia kenttäfolkloristeja moniulotteisemmalla näkemyksellä perinteestä ja sen kannattajista. Varhaiset kansanrunouden tutkijat loivat niin romanttisen ja ihanteellisen perinteenkannattajaimagon, että parhaimmat perinteenkannattajat eivät välttämättä käytännössä sopineet siihen lainkaan. Sinikka Vakimo nostaa eettisenä näkökohtana esiin sen, että vaikka tutkija onkin vastuussa tutkittaville sekä heidän edustamalleen ryhmälle, tutkittavista annettava kuva ei voi olla pelkästään positiivinen. Sellaisena se olisi harhaanjohtava ja tosiasioita poissulkeva.

Epätodellisen imagon rakentaminen tutkittavalle ei silti tänäkään päivänä ole kokonaan ohitettu ongelma. Maahanmuuttajatutkimuksen parissa työskennellyt Line Alice Ytrehus pohtii artikkelissaan kulttuurirelativismin sudenkuoppia ja toiseuden problematiikkaa. Ongelmana hän näkee tavan, jolla ei-länsimaiset kulttuurit esitetään staattisina ja homogeenisina. Sen sijaan, että näistä "perinnekulttuureista" tulevat ihmiset esitetään uskonnon ja tradition ohjaamina, tutkimuksen haasteena pitäisi olla arjen kerroksellisen monimuotoisuuden ymmärtäminen ja kuvaaminen, ei stereotypioiden vahvistaminen. Galit Hasan-Rokem puolestaan analysoi omassa esimerkissään kansanjuhlan etnografiaa, jossa tulkinnat ja dialogit rakentuvat herkästi poliittisesti latautuneiksi.

Tutkimuksen tekeminen perustuu valinnoille alusta asti, ja hyväksymällä tiedostamattomat tulkintaperspektiivit annettuina tutkija voi epähuomiossa osallistua jonkin ryhmän stigmatisointiin. Tekstualisaation kysymyksiä pohtiessaan Vakimo painottaa tasapuolisuutta tutkittavien esiintuomisessa ja painottaa, että huolellisesti rakennettu ja selkeästi esitetty tulkinta vähentää myöhempiä väärinkäyttömahdollisuuksia. Tekstualisaation problematiikkaan liittyy myös Margaret Millsin artikkeli, jossa lähtökohtana ovat "totuuden eri rekisterit". Kysymys palautuu pitkään folklo- 
risteja askarruttaneeseen kysymykseen perinnelajien erilaisista totuusarvoista. Mills nostaa esiin tutkimustekstin etiikan kaksi ulottuvuutta. Yhtäällä on tutkijan suhde tutkimuskohteisiin ja aineistoon heidän luomuksinaan, toisaalla on suhde aiheistosta rakennettuun tekstualisaatioprosessiin.

\section{KENTÄN JA ARKISTOINNIN HAASTEET}

Tutkijan ja tutkittavan kohtaaminen on monisyinen tilanne, jota Tove Ingebjørg Fjell ja Armi Pekkala pohtivat omilla tahoillaan. Fjell osoittaa, kuinka kompleksinen kysymys tutkittavien suostumus tutkimukseen voi olla. Tutkimuslupaa pyydettäessä on varmistettava tutkittavan oikeus tietää tutkimusintentiosta mutta myös se, kenen positiosta käsin lupa annetaan ja kuka on kompetentti myöntämään luvan. Yhteisössään johtavassa asemassa olevan suostumus voi olla joissakin tapauksissa riittävä mutta ei aina kata henkilökohtaista osallistumista jokaisen yksittäisen tutkittavan kohdalla. Pekkala on arvioinut uudelleen omien elämänhistoriallisten haastattelujensa toteutusta kenttäetiikan näkökulmasta. Hän suhteuttaa sitä Hongon muotoilemaan työsopimukseen prosessina, jossa tieto luodaan yhteistyössä tutkijan ja tutkittavan kesken. Pekkala kyseenalaistaa yksiselitteisen ohjeistuksen toimivuuden, mikäli tutkija ei tiedosta selkeästi tilanteen valtasuhteita.

Kaiken kaikkiaan kysymys tutkimusluvasta on kulttuurisidonnainen. Kuten kirjan toimittajat esittävät, kysymisen tapa ja tarve eivät ole kaikissa kulttuureissa samat. Esimerkiksi kirjallisen suostumuksen ja sitoumuksen pyytäminen tutkittavalta voi kontekstista riippuen herättää joko luottamusta tai epäluuloa. Moninkertainen varmistaminen ja luvan kysyminen voikin esimerkiksi kääntyä tutkittavien karkotusmenetelmäksi. Yksiselitteisiä eivät ole myöskään kysymykset anonymiteetin käsittelystä. Niihin vaikuttaa niin tutkittavan, tutkijan kuin aineistoonkin liittyvien hallinnollisten auktoriteettien, kuten arkistojen ja eettisten toimikuntien, näkökannat.

Perinteikkäässä suomalaisessa kenttätutkimuksen oppikirjassa Carsten Bregenhøj (1982) on tiivistänyt periaatteet kerätyn informaation muuttamisesta tutkimusaineistoksi seuraavasti: "Säilytettävän aineistomme me hankimme tallentamalla; tavallaan me siis valmistamme materiaalin itse. Samaten huolehdimme siitä, että tallennettu aineisto säilytetään parhaalla mahdollisella tavalla ja että voimme päästä käsiksi aineistoon uudelleen. Siksi rekisteröimme, luetteloimme, systemaattistamme ja järjestämme aineiston. Näin aineistoa voidaan käyttää uudelleen. (1)" Näitä transformaatiovaiheita, jotka materiaali käy läpi, Bregenhøj on kutsunut kuvaavasti suodattimiksi. Kysymys on valinnoista, joita ohjaa kulttuurikohtainen ymmärrys aineiston luonteesta. Sittemmin Hongon (1990) folk:loreprosessiksi määrittelemään etnografisen tutkimusaineiston elinkaareen liittyy erottamattomasti arkistoinnin eettiset ja poliittiset dilemmat, jota Barbro Klein on omassa artikkelissaan problematisoinut muun muassa autoritatiivisen etnografian käsitteen kautta; se mikä on arkistoitu, on ymmärretty tavalla tai toisella normatiiviseksi, esimerkiksi "aidoksi perinteeksi". Klein pohtii paitsi etnografian myös kyselyaineistojen ja kilpakirjoitusten käyttöä ja niiden antamaa kuvaa tutkittavasta 
ilmiöstä. Hänen mukaansa usein voidaan puhua siistitystä folkloreperinnöstä, josta sitä edustavien todellisten ihmisten toimijuus ja valta on riistetty.

\section{KUKA LOHDUTTAISI TUTKIJAA?}

Tutkimuseettiset oppaat ovat itse joutuneet kriittisen arvioinnin kohteeksi Judy Rangnesin artikkelissa. Kulttuurintutkijan ottein Rangnes osoittaa, kuinka kaikki tutkimusetiikka perustuu arvoihin, jotka ovat viime kädessä aina kontekstuaalisia ja varioivat kulttuurisesti. Tästä syystä takuuvarmat yleispätevät" eettiset reseptit", joita kuuliaisesti noudattamalla vältyttäisiin värinkäytöksiltä tutkimusta tehtäessä, ovat mahdottomuus. Vaikka tarkoitukset ja periaatteet ovat hyvät, ne voivat käytännössä toteutua monenlaisina tarinoita, jotka eivät aina vastaa eettisiä ihanteita kaikissa tilanteissa. Esimerkiksi tutkittavien suojelu, mahdollisesti aiheutuvan vahingon suhteellisuus, tutkittavuuden rajat tai tabuluonteisten aiheiden käsittely ovat kulttuurintutkijan kohtaamissa tilanteissa eri tavoin kontekstuaalisia eikä universaalia eettistä ohjeistusta ole siksi helppo rakentaa.

Varmimpana keinona tutkimusetiikan tärkeyden ymmärtämiseen ja sen kehittämiseen Research Ethics -teos osoittaa tehokkaan ja tarkoituksenmukaisen metodologisen koulutuksen. Tutkimusetiikan edistämisen tulee kuulua luonnollisena osana tutkijakoulutuksen perusopetukseen. Nähdäkseni toimiva tapa ei kuitenkaan ole erillinen etiikkakurssi. Sen sijaan tutkimusetiikan ajantasainen pohdinta integroituna tietoisesti kaikkeen metodologiseen opetukseen rakentaa sille luontevan paikan tutkijan ammatillisessa osaamisessa. Etiikkahan ei ole tutkimuksen erillisteema, vaan se liittyy koko prosessiin suunnitelmasta julkaisuun sekä myöhempiin aineiston uudelleenkäyttötilanteisiin, ei pelkästään aineiston keruuseen ja säilytykseen. Näiden kysymysten käsittelyyn tämä teos antaa niin hyviä eväitä, että se tulisi sisällyttää tutkintovaatimuksiin.

Eettisen koodiston tulee kuitenkin ulottua myös toiseen suuntaan, tutkijan oikeuksien turvaamiseen. Alver ja Øyer eivät aseta yksittäistä tutkijaa yksin vastuuseen toteutetun tutkimuksen seurauksista ja tulkintatavoista. Tutkimus ei suinkaan tapahdu tyhjiössä vaan elimellisenä osana tiedeyhteisön toimintaa. Tutkimuslaitoksen, johon tutkija on sitoutunut, tulee olla valmis seisomaan niiden periaatteiden takana, jotka on suunniteltu ja hyväksytty suojaamaan myös tutkijan integriteettiä ja oikeuksia. Tieteen tekeminenkin on omaan aikaansa sidottua. Tutkimuksen tehtävänä on myös korjata itseään, ei löytää viimeistä sanaa, joka pätisi hamaan tuomiopäivään asti. Myös eettisten periaatteiden ja vaatimusten on nähtävä syntyvän ja toimivan historiallisissa ja kulttuurisissa konteksteissaan ja kehittyvän jatkuvan keskustelun ja arvioinnin tuloksina.

\section{VIITTEET}

1. Allekirjoittaneen kursivointi. 
Tuija Hovi

\section{KirJallisuUs}

BREGENHØJ, CARSTEN 1982: Folkloristinen suodatin. - Suojanen, Päivikki \& Saressalo, Lassi (toim.), Kulttuurin kenttätutkimus. Tampere: Tampereen yliopiston kansanperinteen laitos.

CLAKEBURN, HENRIIKKA \& MUSTAJOKI, ARTO 2007: Tutkijan arkipäivän etiikeka. Tampere: Vastapaino.

HALLAMAA, JAANA \& LAUNIS, VEIKKO \& LÖTJÖNEN, SALLA \& LÖYTTY, OLLI (toim.) 2006: Etiikkaa ibmistieteille. Tietolipas 211. Helsinki: SKS.

HONKO, LAURI 1990: Folkloreprosessi. - Sananjalka 32.

KUULA, ARJA 2006: Tutkimusetiikkea. Aineiston bankinta, käyttö ja säilytys. Tampere: Vastapaino.

TUTKIMUSEET'TINEN NEUVOTTELUKUNTA 2002: Hyvä tieteellinen käytäntö ja sen loukkausten käsitteleminen. Helsinki: Tutkimuseettinen neuvottelukunta.

Filosofian tohtori Tuija Hovi on turkulainen uskontotieteilijä ja apurahatutkija, jonka tutkimuskenttänä on uuskarismaattinen liike Suomessa. 